EUROPEAN ORGANIZATION FOR NUCLEAR RESEARCH

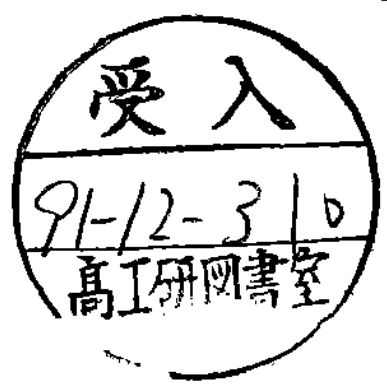

\title{
THE NEW CERN-ISOLDE ON-LINE MASS-SEPARATOR FACILITY AT THE PS-BOOSTER
}

E. Kugler1), D. Fiander 1), B. Jonson 2), H. Haas1), A. Przewloka3), H. L. Ravn1), D.J. Simon1), K. Zimmer4) and the ISOLDE Collaboration

1) CERN, CH-1211 Geneva 23, Switzerland

2) Dept. of Physics, Chalmers University of Techbnology, Göteborg, Sweden

3) Institute of Physics, J. Liebig-Universität, Giessen, Germany

4) Institute of Physics, Johannes Gutenberg Universität, Mainz, Germany

\section{ABSTRACT}

The ISOLDE On-Line Isotope Separators have been operated since 1967 at the CERN-SC. This $600 \mathrm{MeV}$ proton synchrocyclotron had to be shut down after 33 years of service in December 1990 and it was decided to move ISOLDE to a new experimental area. The new on-line mass-separator facility is now under construction at the CERN PS-Booster. This accelerator provides an average current of about $2 \mu \mathrm{A}$ of $1 \mathrm{GeV}$ protons in very short high intensity pulses at low repetition rate. The beam can hit either one of the two target stations, the General Purpose Separator (GPS), a reconstructed ISOLDE-2 type machine (which can deliver beams simultaneously into three beamlines), and the High Resolution Separator (HRS), which is essentially the slightly modified ISOLDE-3 separator. The central GPS beam line and the HRS feed a common beam transport system to which most of the experiments will be connected. The new facility will be taken into operation in spring 1992.

To be presented at the Twelfth International Conference on Electromagnetic Isotope Separators and Techniques Related to their Applications

Sendai, Japan, 2 - 6 September 1991

To be published in Nucl. Instrum. \& Methods B 


\section{INTRODUCTION}

The On-Line Isotope Separator ISOLDE was constructed at the CERN 600 $\mathrm{MeV}$ Synchro-Cyclotron and came into operation in 1967 [1] as one of the first machines of its kind. In 1972/73 the synchro-cyclotron and the isotope separator were upgraded to what became known as ISOLDE-2 (IS-2) [2]. The result was an increase in proton beam intensity to $2.8 \mu \mathrm{A}$ and an elaborate ion beam transport system which allowed to deliver ions to several experiments at the same time. These improvements together with an extensive work on target and ion source techniques [3] lead to a wealth of experimental results not only in nuclear but also in atomic and solid state physics and also allowed some medical applications. In the 1980s a second isotope separator with enhanced ion optical qualities - ISOLDE-3 (IS-3) was constructed at the synchro-cyclotron $[4,5]$. This installation enabled some new unique experiments, e.g. on-line nuclear orientation [6] and one absolutely requiring isobaric mass separation [7]. The total number of 8hour shifts, given to physics, was brought close to 400 per year.

During all these years ISOLDE has been the world's largest facility for production and study of radioactive nuclei from all regions of the nuclidic chart [8].

In spite of its renowned excellent performance the CERN-SC, the oldest and smallest of CERN's accelerators, had to be shut down at the end of 1990 after a remarkable 33 years of service. Following the decision to maintain the ISOLDE physics as part of CERN's scientific programme a new site for ISOLDE was found $[9,10]$ at the CERN Proton-Synchrotron Booster

\section{THE PS-BOOSTER}

The PS-Booster (PSB) is a stack of four small synchrotrons preaccelerating protons delivered by a Linac to $1 \mathrm{GeV}$ before they are injected into the CERN Proton-Synchrotron (PS) which in turn supplies particles to CERN's high energy machines.

Over the years the total intensity of the four ring PSB was pushed to 3.2 $10^{13}$ protons/pulse [11]. Since the available PSB cycles can not fully be used by the CERN-PS and the accelerators it feeds, about one pulse of two in a typical PS supercycle would be available to isotope production at ISOLDE 
(fig. 1). This current is equivalent to about $2.1 \mu \mathrm{A}$ of protons. Depending on the future of the heavy ion beam programme at CERN particles other than protons could also be provided to ISOLDE as projectiles (e.g. ${ }^{3} \mathrm{He}$ ).

The time structure of the Booster beam differs considerably from the previously used SC beam, as the PSB delivers very short high intensity pulses at low repetition rate (Table 1).

\section{Table 1}

\begin{tabular}{|l|r|}
\hline Beam energy & $1 \mathrm{GeV}$ \\
\hline Max. intensity on target & $3.210^{13} \mathrm{p} /$ pulse \\
\hline Pulse length & $2.4 \mu \mathrm{s}$ \\
\hline Repetition time (typ.) & $1.2-2.4 \mathrm{~s}$ \\
\hline Current (max) & $2.1 \mu \mathrm{A}$ \\
\hline
\end{tabular}

\section{LAYOUT}

The 3-D view of the new facility is given in fig. 2. The protons from the PS-Booster are delivered to the ISOLDE target zone via a new, about $100 \mathrm{~m}$ long, underground transfer line. One of the two ISOLDE target positions is in the straight line, the other requires a bend of $400 \mathrm{mrad}$. The bending magnets are laminated with the possibility in mind that one would like to run the two ISOLDE target stations in beam sharing mode (e.g. development work on one station needing only occasional proton pulses while a production run is going on at the other machine).

The two isotope separators are arranged such that a beam from either machine can be fed into a common beam distribution system to which almost all of the experiments in the $700 \mathrm{~m}^{2}$ experimental hall are connected. The General Purpose Separator (GPS), where three beams within a certain mass range can be selected and delivered simultaneously into three beamlines, is constructed similar to ISOLDE-2. The High Resolution Separator (HRS) is essentially the slightly modified ISOLDE-3 machine.

Great attention has been paid to the safe handling of the highly radioactive ISOLDE target/ion source units. The well proven concept of changing, storing and removing targets with a mobile industrial robot is taken over from IS-2\&3 [12]. This robot goes on rails to either one of the two target stations and can be parked outside the radiation zone when not in use. Used targets will be stored on shelves in the walls of the robot galleries. 
Directly attached to the primary radiation zone is a small controlled laboratory area with a hot cell and fume cupboards where, after a suitable cooling period, radioactive targets can be inspected and repaired. Radioactive material does not have to leave this zone except for disposal. Also located in this building are rooms for the Health Physics Services . Much effort is being put into adequate shielding and ventilation of the radioactive zones [13]. In addition to steel and concrete shielding blocks around the ISOLDE targets the whole zone is buried under up to $8 \mathrm{~m}$ of earth. The ventilation system is specially designed to ensure that radioactive contamination is kept within the confined area in case of an accidental release, e.g. from a leaking target, and that the activated air stays long enough inside the sealed area to decay. Also the exhaust gas from the vacuum pumps is stored in steel tanks before being released through a series of filters.

\section{THE GENERAL PURPOSE SEPARATOR (GPS)}

The smaller of the two isotope separators (see fig.3) is conceived as an easy to operate, flexible machine. Its centerpiece is a double focussing $70^{\circ}$ magnet with a mean bending radius of $1.5 \mathrm{~m}$. The main data can be found in Table 2.

Its front end, a copy from IS-3 and fully interchangeable with the other separator, contains the target coupling flange, the $60 \mathrm{kV}$ acceleration gap and an electrostatic quadrupole triplet. In the simplest mode of operation (with a point ion source) this lens makes it possible to form the parallel beam needed at the entrance to the magnet. As an option an additional quadrupole doublet is installed in front of the magnet in order to cope with more difficult ion sources (e.g. a slit source). The ion optical calculations were done in Mainz and at CERN using the program GIOS developed at Giessen University [14]. The result of these calculations is shown in fig. 4.

Following the spirit of IS-2 a new switchyard (Fig.5) was constructed which will allow to select three ion beams within the mass range of $\pm 15 \%$ from the central mass and to transport these beams at the same time to three experiment stations in the experimental hall. This switchyard is built up of pairs of electrostatic cylinder-shaped deflector plates, one pair on either side of the central mass. The selection of mass is achieved by moving them parallel to the focal plane. To make best use of the space in the 
experimental hall both side beams are taken out to the left of the central mass.

\section{THE HIGH RESOLUTION SEPARATOR (HRS)}

The complete ISOLDE-3 isotope separator will be moved to the new site with only a few modifications. The most significant change is that the beam bending in the two magnets will now be in the opposite sense, thus taking away the need for an electrostatic quadrupole lens to create an additional intermediate focus in front of the second magnet. Ion optical calculations[15] have shown that also in the new configuration the original goal for IS-3 of reaching a mass resolving power of more than 30.000 can still be maintained. It should here be mentioned that at the new site the separator will not be exposed to magnetic stray field that could cause problems as observed at the synchro-cyclotron. A summary of the most important data for the HRS can be found in Table 3.

\section{THE BEAM DISTRIBUTION SYSTEM}

A main objective in the design of the facility was to make best use of the available space, particularly of the experimental hall. The most versatile mode of operation is to to be able to supply the experiments with ions from either separator. To reach this goal a "merging switchyard" has been designed (see fig.6). The beam coming from the HRS or the central beam of the GPS are bent close to the final direction with the help of cylindershaped deflector plates. The final kick is given by a parallel plate condensor which can be excited with one or the other polarity. Since there are no moving parts in this "merging" switchyard fast switching would be possible, but obviously only one beam at a time can pass through it. This design is the inverse of the well proven standard IS-3 switchyard construction.

The beam distribution system is taken from IS-3 and further equipped with two new five-way switchyards. An example of the ion optical calculations for one selected beam line branch is shown in fig. 7. Most of the experiments will be connected to these beam lines.

At the GPS two short beam lines will accept ions from the low and the high mass side of the mass spectrum. These two side beam lines can be used in parallel with the central line. 


\section{THE SEPARATOR FRONT ENDS}

The well proven front end construction as well as the target design are taken over from IS-3. A few modifications were made, mainly concerning the drive mechanism for the extraction electrode and the position of insulators. All services (electric power, water, compressed air etc) are connected with quick couplings in order to speed up the exchange of a complete front end in the highly radioactive zone.

The whole front end is enclosed in a metallic air tight cage with ample space around the machine. Apart from preventing access to the high voltage parts of the front ends this enclosure also serves several other purposes: 1 . It defines the ground potential around the separators. 2 . The cage is supplied with a continuous flow of dry air to prevent sparking in the air gap and to limit the formation of nitric acid created by the passage of the high energy particles through air. 3. This volume is kept under slight underpressure and serves as a confinement in case of accidental release of radioactivity from a target unit.

\section{THE VACUUM SYSTEM}

There is a distinct separation between the pumping of the separators, where substantial amounts of radioactive gases and vapors have to be pumped away, and the much cleaner beam transport system. The gas from the pumps serving the separators is collected in steel vessels with a total capacity of about $20 \mathrm{~m}^{3}$ and released through active carbon and absolute filters when the activity has sufficiently decayed.

All pumps are turbomolecular pumps separated from the vacuum chambers by valves as to avoid frequent starts and stops. Only a few rotary pumps are used for roughing and backing of the whole system. All pumping sequences and vacuum interlocks are controlled with an industrial programmable logic controller (Simatic) which is linked to the ISOLDE control system.

\section{THE ACCELERATION VOLTAGE}


The major technological problem of the project is caused by the time structure of the Booster-beam, the instantaneous beam current being as high as $2 \mathrm{~A}$. This beam produces intense ionization of air in its path both in front of and behind the target and also, due to the cascade of high energy particles, in the air surrounding the target. In a conventional isotope separator the target and ion source are held on high voltage with respect to their surroundings. Under these conditions any normal high voltage supply might break down during beam impact. Our solution to this problem is a pulsed high voltage supply which in $35 \mu$ s brings the voltage down to zero just before beam impact and restores it to the regulated value shortly thereafter $(10-20 \mathrm{~ms})$. The circuit consists of a $\mathrm{HV}$ pulser (fig. 8) whose thyratron is triggered by the timing signals coming from the PS-Booster. The pulse transformer produces a short pulse of equal voltage but with opposite polarity which is superimposed at the HV terminal of the ISOLDE target. This pulsed power supply has been constructed at CERN and is now ready for testing. However, the final test with the real beam load will be possible only when the isotope separator goes on-line early 1992.

The HV supply, the isolating transformers and all target and ion source supplies are located in a dedicated room above the HRS magnets. This room is lined with sheet metal forming a Faraday cage. From here high voltage and the target and ion source power are fed to the target areas via coaxial ducts which are connected to the front end Faraday cages. Thus all critical parts of the separators are enclosed in a uniform ground potential envelope.

\section{THE CONTROL SYSTEM}

With the move of the ISOLDE facility to its new site a modern control system for both separators and the beam lines will be implemented. It is based on inexpensive personal computers running under MS-DOS and Microsoft Windows and makes use of the CERN-wide installed network. Details of this control system are given in another contribution to this conference [16].

\section{STATUS OF THE PROJECT AND OUTLOOK}


At the time of this conference the civil engineering work of the whole facility has been completed and the necessary services such as power, ventilation, cooling water etc. are being installed to be ready by the end of October 1991.

At the same time the new beam line going from the Booster to the two ISOLDE target stations is being built up in the tunnel which was constructed already in 1990. A test of the beam transfer is foreseen for December 1991, leaving some time for implementing corrections, if necessary, before the start-up of the ISOLDE facility.

The GPS magnet is at present undergoing thorough field measurements at CERN. The quadrupole lenses for the first phases of installation are available. A new front end is being finished. The GPS switchyard and all vacuum chambers are scheduled to be delivered and installed by the end of the year.

The IS-3 machine is being kept in working conditions until the end of September 1991 for tests with the new HV supply and will then be decommissioned. The heavy magnets are to be put in their new positions before the shielding walls of the separator zones are finished.

The installation of the ISOLDE separators, the beam lines and all related equipment will start in October 1991 and is planned to be done in four phases: first the GPS will be built up and become operational in March 1992. Then the main part of the beam line is moved into the experimental hall. Thirdly the side branches of the beam line with two new switchyards will be added. The final phase is the installation of the HRS planned for the annual shut-down of the CERN-PS in January and February 1993.

So far ten major ISOLDE experiments have requested beam time [17]. It is already evident that the experimental hall will be too small to accept all auxiliary equipment for the experiments. Therefore it is planned to add a light building with two floors at the long side of the hall housing lasers, computers and other experimental equipment. 


\section{ACKNOWLEDGEMENTS}

The authors would like to thank the CERN Directorate for its determination to maintain ISOLDE at CERN and for the generous investment in the construction of the new premises. We thank $R$. Kirchner, A.C. Mueller, E.W. Otten, J.W. Petersen and G. Walter, all members of the ISOLDE Technical Committee, for their invaluable advice during the planning period for the new facility. Our thanks go to the PS Division for hosting ISOLDE as a new customer for the PS Booster and the extensive support in human and financial resources. We acknowledge the many contributions by the AT, MT and ST Divisions needed to make the project a reality. 
REFERENCES:

1. The ISOLDE Isotope Separator Facility at CERN (Ed. A. Kjelberg and G. Rudstam) CERN 70-3 (1970).

2. H.L. Ravn, Phys. Rep. 54 (1979) 201.

3. H.L. Ravn, Nucl. Instrum \& Methods B26 (1987) 72.

4. B.W. Allardyce and H. L. Ravn, Nucl. Instrum. \& Methods B26 (1987) 112.

5. C. Geisse, H. Wollnik, B. W. Allardyce, E. Kugler and K. Schlösser, Nucl. Instrum. \& Methods B26 (1987) 120.

6. K. Schlösser et al., Hyperfine Interactions 43 (1988) 141.

7. A. Garcia et al., $\beta^{+}$decay of ${ }^{37} \mathrm{Ca}$, accepted for publication in Phys. Rev. Lett. (1991).

8. H. Ravn in ISOLDE Users' Guide (Ed. H.J. Kluge), CERN 86-05 (1986).

9. D.J. Simon, Transfer of ISOLDE to the PS-Booster, PS/PA-EP Note 90-13 Rev.1.

10. M. Albrow, R. Billinge, F. Dydak, B. Jonson and A. Richter, The ISOLDE Facility at the PS Booster, CERN/PSCC/89-29, July 1989.

11. B.W. Allardyce, R. Billinge, C.E. Hill, C. Metzger, K. Schindl, H. Schoenauer and D.J. Simon, ISOLDE: A new Client for the CERN PS Booster, Proceedings of the 2nd European Particle Accelerator Conference EPAC-90, Nice, 12-16 June 1990.

12. T. Bjørnstad, E. Hagebø, P. Hoff, O.C. Jonsson, E. Kugler, H.L. Ravn, S. Sundell and B. Vosicki, Nucl. Instrum. \& Methods B26 (1987) 174.

13. A.H. Sullivan, Radiation Safety Considerations for the new ISOLDE Facility using the PS Booster Beam, CERN-RCP/90/XV/68 (1990).

14. H. Wollnik, J. Brezina, M. Berz and W. Wendel, Proc. AMCO-7, GSI-Rep. THD-26 (1984) 679.

15. C. Geisse, Private Communication.

16. O.C. Jonsson et al., The Control System of the CERN-ISOLDE On-Line MassSeparator Facility, to be published in the Proceedings of this Conference.

17. ISOLDE COMMITTEE, Secretary J. Eades, PPE Division, CERN. 
Table 2

\title{
GENERAL PURPOSE SEPARATOR
}

\section{ION SOURCE}

Emittance:
point source:
diam $0.4 \mathrm{~mm}$ and $\pm 25 \mathrm{mrad}$
slit source(option):
horizontal: width $0.4 \mathrm{~mm}$ and $\pm 25 \mathrm{mrad}$
vertical: height $10 \mathrm{~mm}$ and $\pm 5 \mathrm{mrad}$

\section{LENS SYSTEM}

Electrostatic quadrupole triplet

Electrostatic quadrupole doublet (option)

Parallel beam at magnet entrance

\section{MAGNET}

Type:

H-magnet

Bending radius

Bending angle

Pole shoe width

Gap hcight:

Entrance angle

Ficld curvature (entrance)

Exit anglc

Focal length

Inclination of focal plane

(double focussing)

Maximum flux density

Homogeneity

Mass resolving power

(calculated)

$1500 \mathrm{~mm}$

$70^{\circ}$

$380 \mathrm{~mm}$

$60 \mathrm{~mm}$

$18,6^{\circ}$

$3940 \mathrm{~mm}$

$19.9^{\circ}$

$1684 \mathrm{~mm}$

$33.3^{\circ}$

$0.45 \mathrm{~T}$

5.10-4

2400 (for $20 \mathrm{~mm}$ mrad beam)

\section{SWITCH YARD}

Acceptance:

Central beam

Side beams

Minimum distance

Deflectors

\author{
$\pm 15 \%$ of central mass \\ undeviated \\ 1 on high mass side $(0$ to $+15 \%)$ \\ 1 on low mass side (0 to $-15 \%$ ) \\ $20 \mathrm{~mm}$ from central to side beam \\ mobile clectrostatic cylinder condensers, \\ mean radius $600 \mathrm{~mm}$, gap width $30 \mathrm{~mm}$
}


Table 3

\section{HIGH RESOLUTION SEPARATOR}

\section{ION SOURCE}

Emittance:

point source:

diam $0.4 \mathrm{~mm}$ and $\pm 25 \mathrm{mrad}$

slit source (option):

horizontal: width $0.4 \mathrm{~mm}$ and $\pm 25 \mathrm{mrad}$

vertical: height $10 \mathrm{~mm}$ and $\pm 5 \mathrm{mrad}$

FIRST SEPARATOR STAGE

\section{LENS SYSTEM}

Electrostatic quadrupole triplet lens

Electrostatic quadrupole doublet lens

Electrostatic quadrupole singlet lens3

\section{FIRST MAGNET}

$\begin{array}{ll}\text { Type } & \text { C-magnet } \\ \text { Bending radius } & 1000 \mathrm{~mm} \\ \text { Bending angle } & 90^{\circ} \\ \text { Pole shoe width } & 420 \mathrm{~mm} \\ \text { Gap height } & 110 \mathrm{~mm} \\ \text { Exit angle } & 19^{\circ} \\ \text { Maximum flux density } & 0.7 \mathrm{~T} \\ \text { Focal length } & 1986 \mathrm{~mm} \\ \text { Inclination of focal plane } & 22^{\circ} \\ \text { (double focussing) } & \end{array}$

4. HIGHER ORDER CORRECTION ELEMENTS

1 electrostatic multipole (32-poles in octopole configuration)

pole face windings in the magnet (hexapolc)

\section{SECOND SEPARATOR STAGE}

\section{LENS SYSTEM}

Electrostatic quadrupolc doublet

Electrostatic quadrupole singlet (after the magnet)

\section{MAGNET}

$\begin{array}{ll}\text { Type } & \text { C-magnct } \\ \text { Bending radius } & 1000 \mathrm{~mm} \\ \text { Bending angle } & 60^{\circ} \\ \text { Pole shoe width } & 420 \mathrm{~mm} \\ \text { Gap height } & 110 \mathrm{~mm} \\ \text { Field curvature } & 4100 \mathrm{~mm} \\ \quad \text { (entrance and exit) } & \\ \text { Maximum flux density } & 0.7 \mathrm{~T}\end{array}$

\section{HIGHER ORDER CORRECTION ELEMENTS}

2 electrostatic multipoles (32-poles in octopole configuration)

pole face windings in the magnet (hexapole)

Total mass resolving power $\quad 7000$ without higher order corrections (measured at IS-3) 10600 with higher order correction 


\section{FIGURE CAPTIONS:}

Fig. 1 A typical supercycles of the CERN-PS (upper curve) and PS-Booster (lower curve). The ISOLDE cycles are shaded.

Fig. 2 A 3-D view of the new ISOLDE facility. The whole area, except the experimental hall, is buried under up to $8 \mathrm{~m}$ of earth.

Fig. 3 Layout of the ISOLDE facility

Fig. 4 The ion optics of the GPS, including the arrangement of deflector plates in the switchyard (light mass side) and the telescope for the beam transport to the experimental hall. The insert shows the cross section in the focal plane of isobaric beams 99, 100 and 101 as obtained from third order calculations.

Fig. 5 The GPS switchyard. Clearly visible are the cylinder-shaped electrostatic deflector plates on either side of the central mass. These deflectors are moved parallel to the focal plane.

Fig. 6 The merging switchyard.

Fig. 7 The ion optics of the HRS. Also shown is the beam transport through the merging switchyard and one branch of the beamline.

Fig. 8 Schematic diagram of the H.V. pulser. 


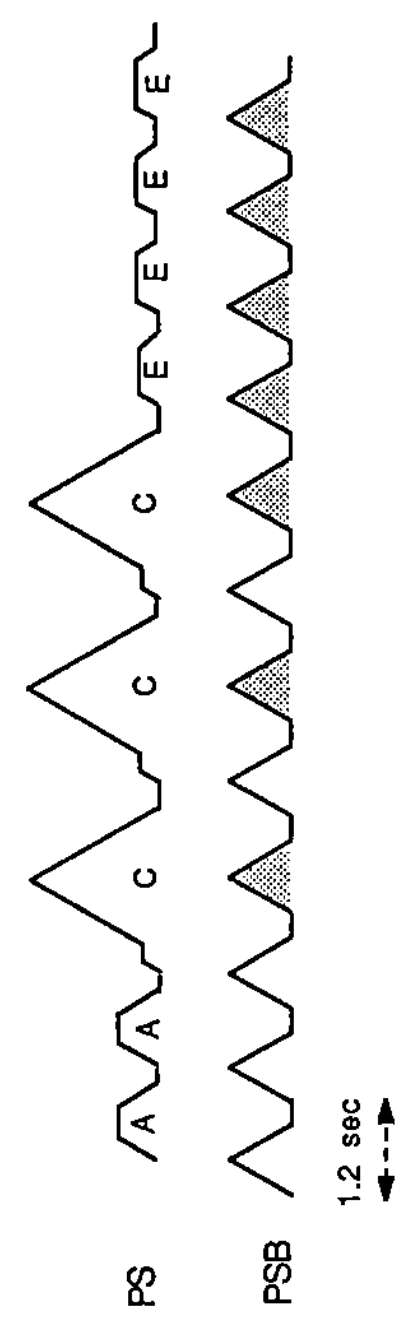




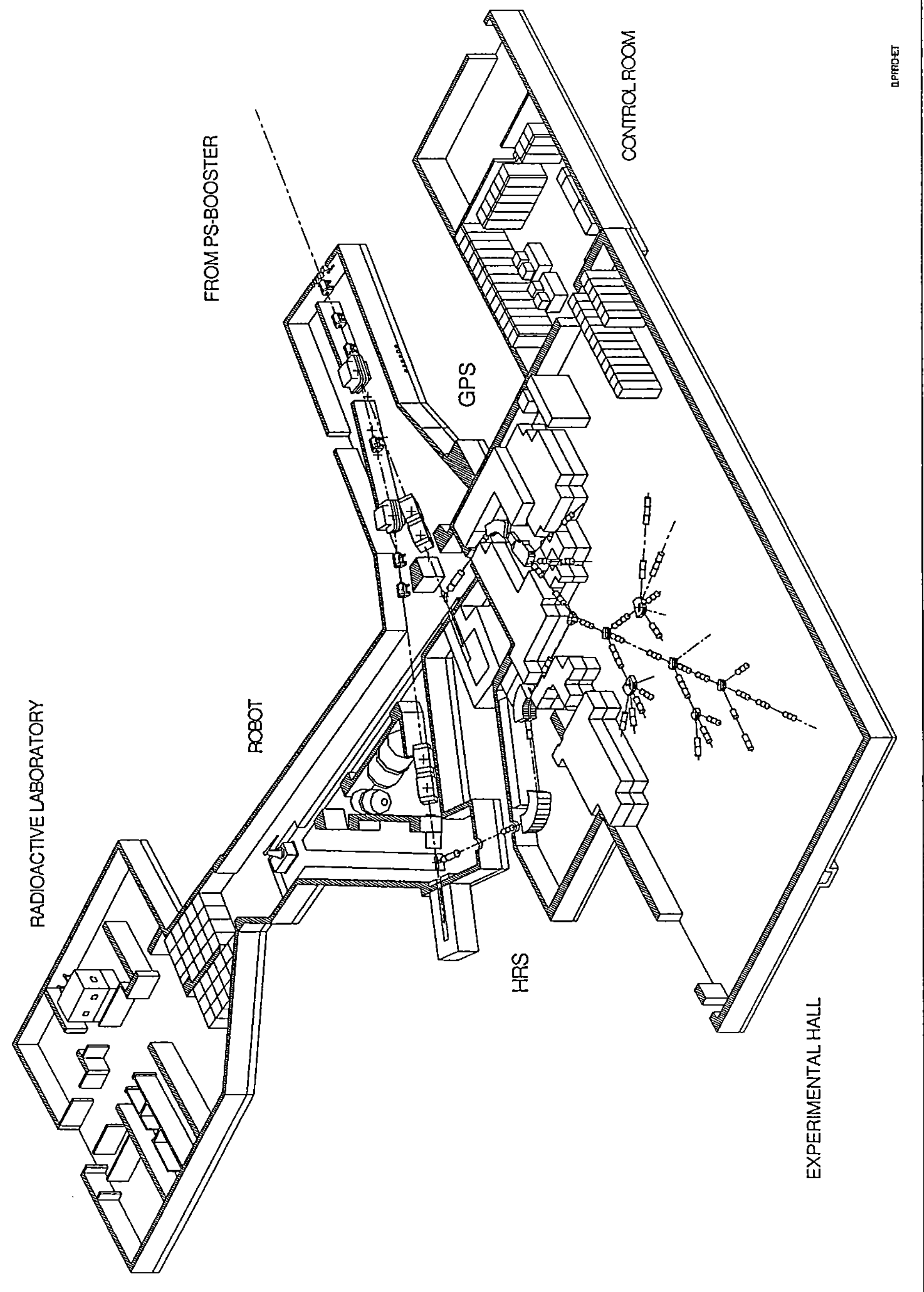




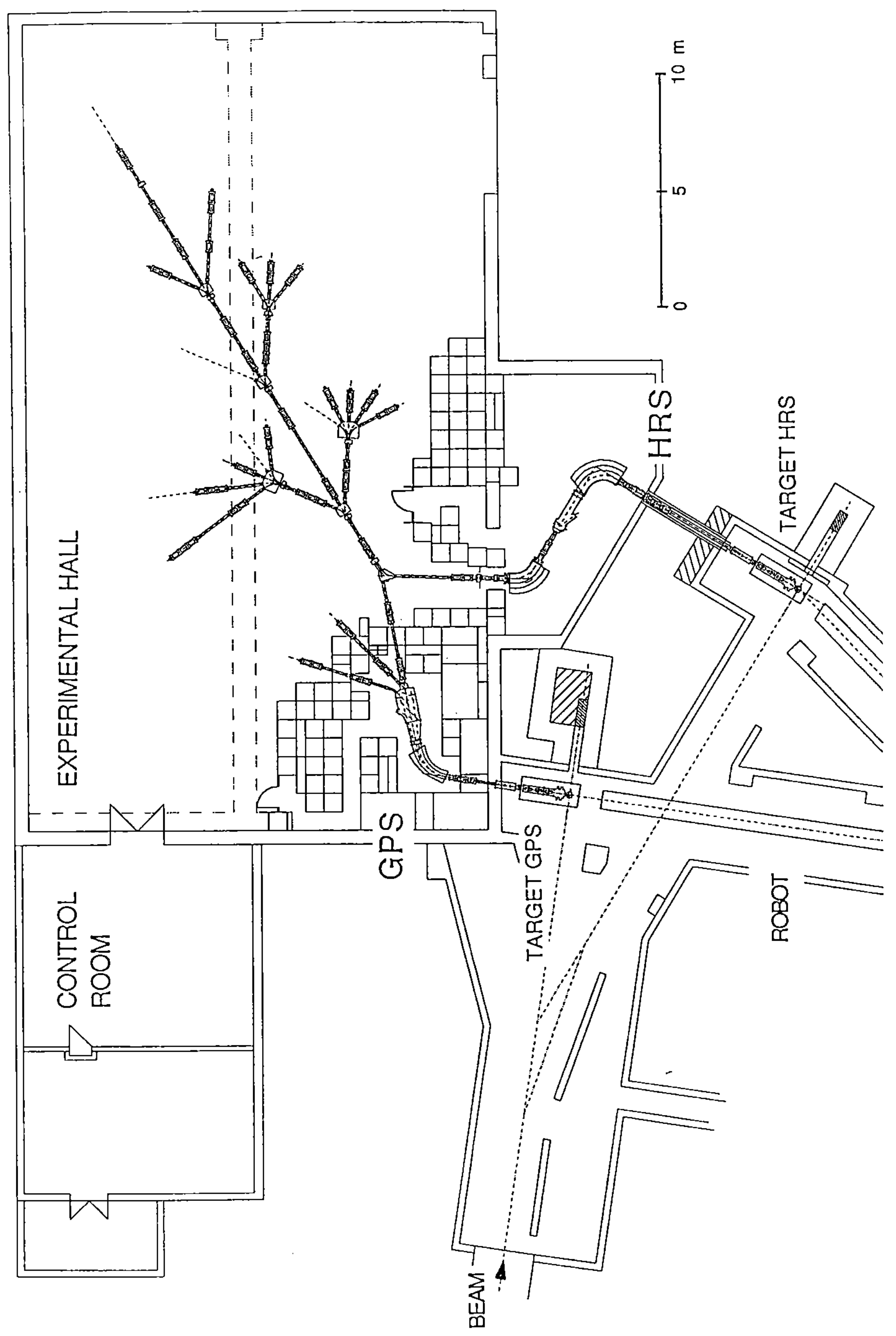




\section{GPS}

Switch yard - light mass side

Andreas Przewloka

II. Pbysikalisches Institut D-6300 GIESSEN
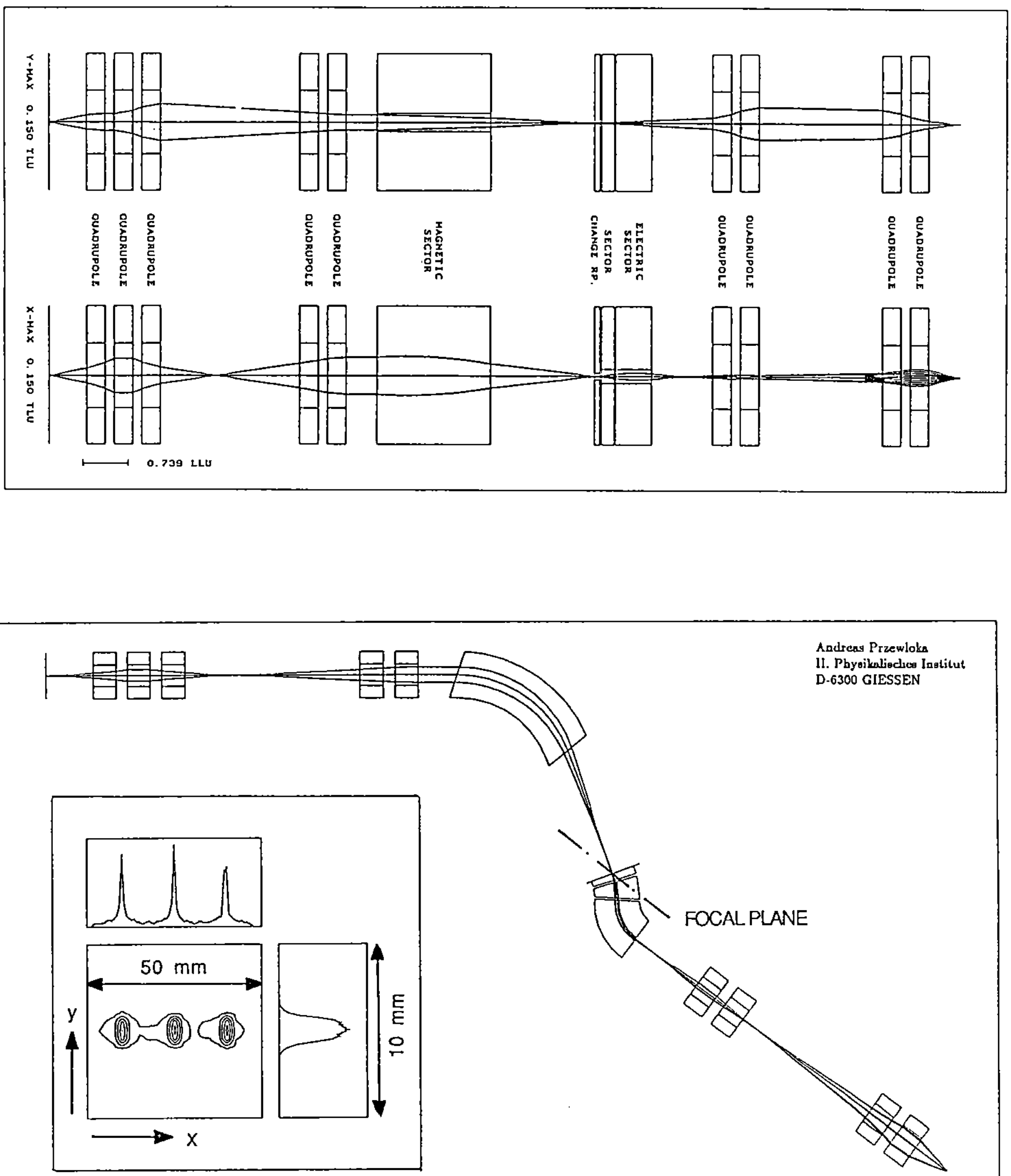


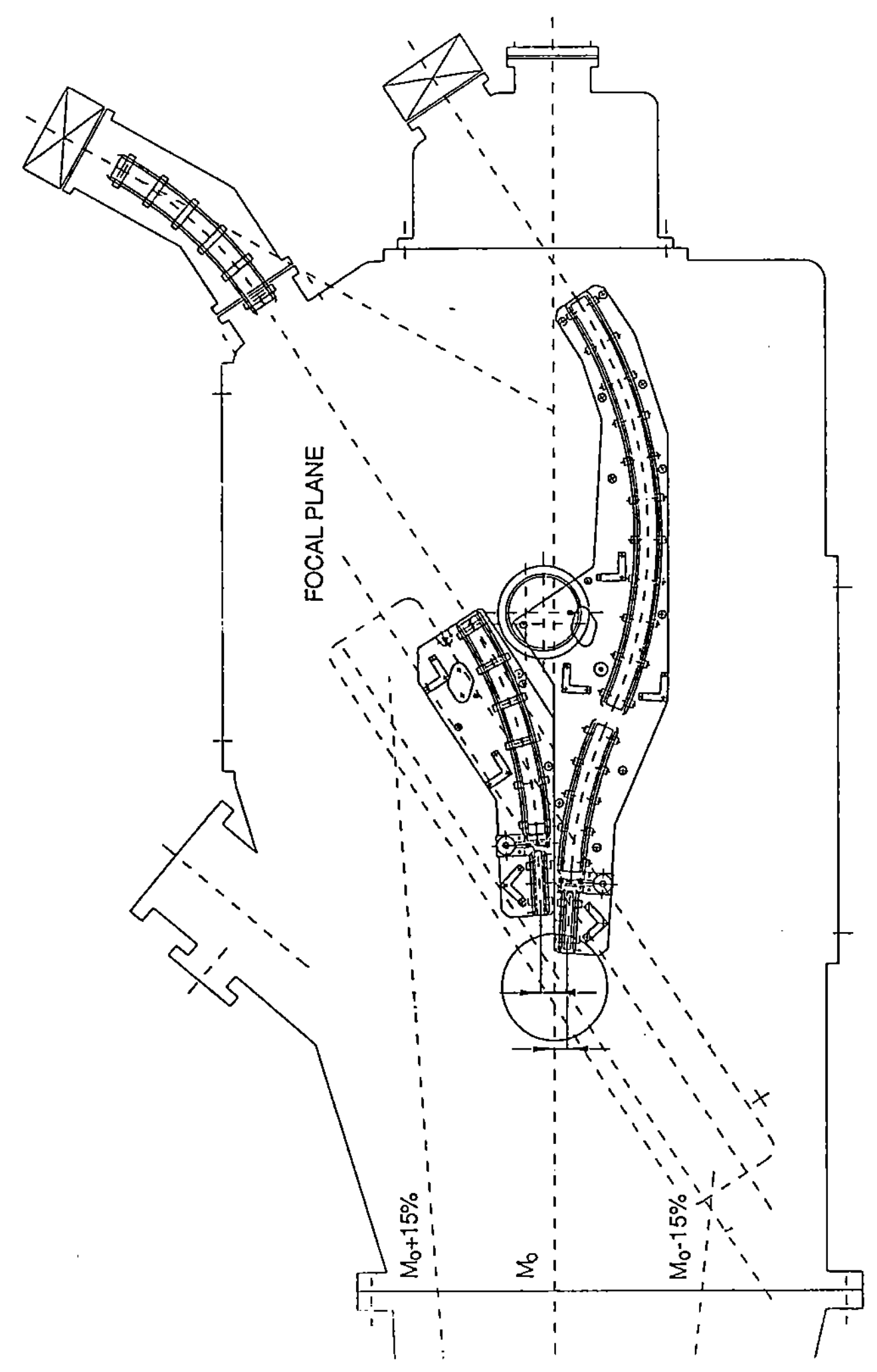




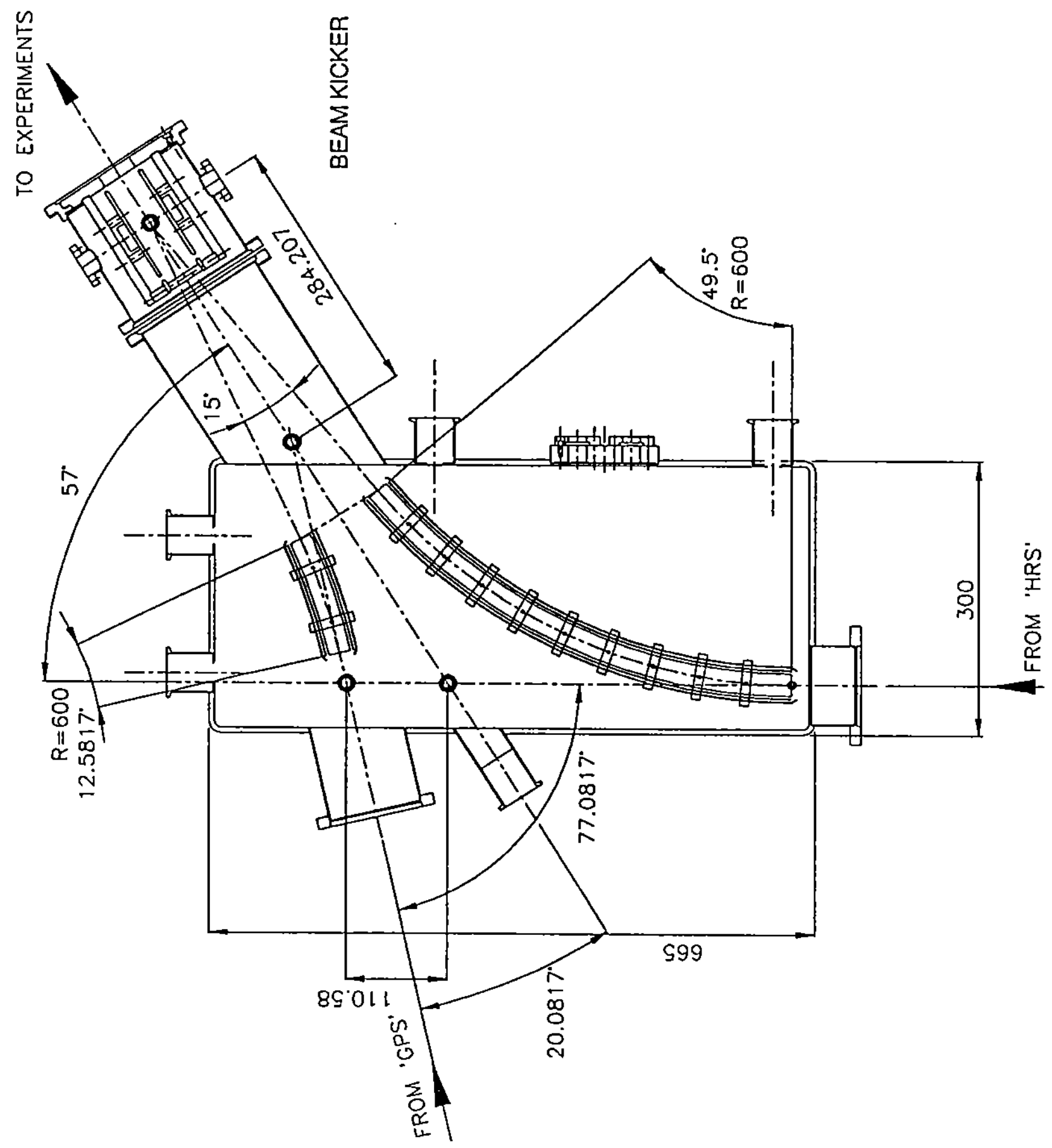



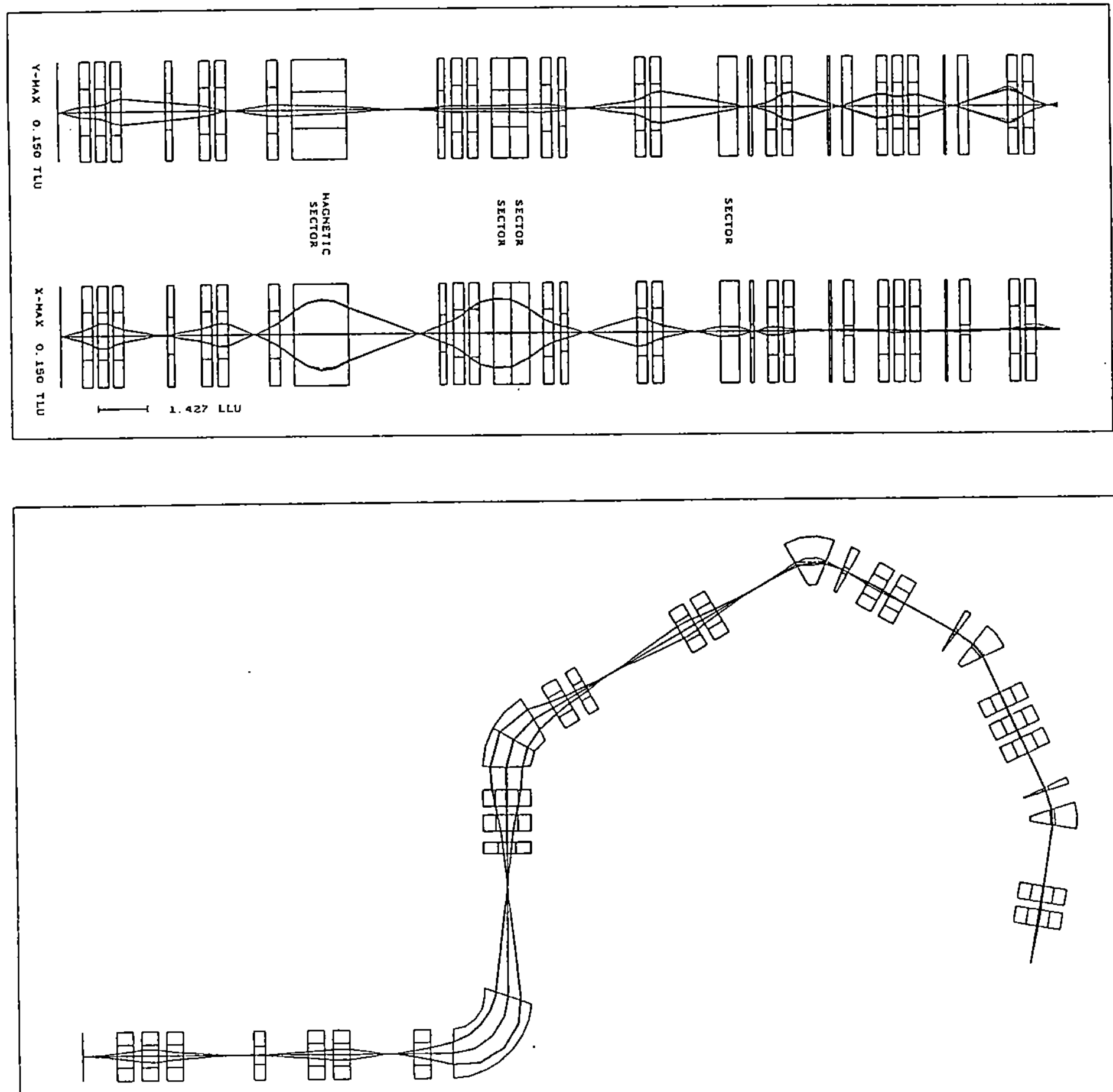


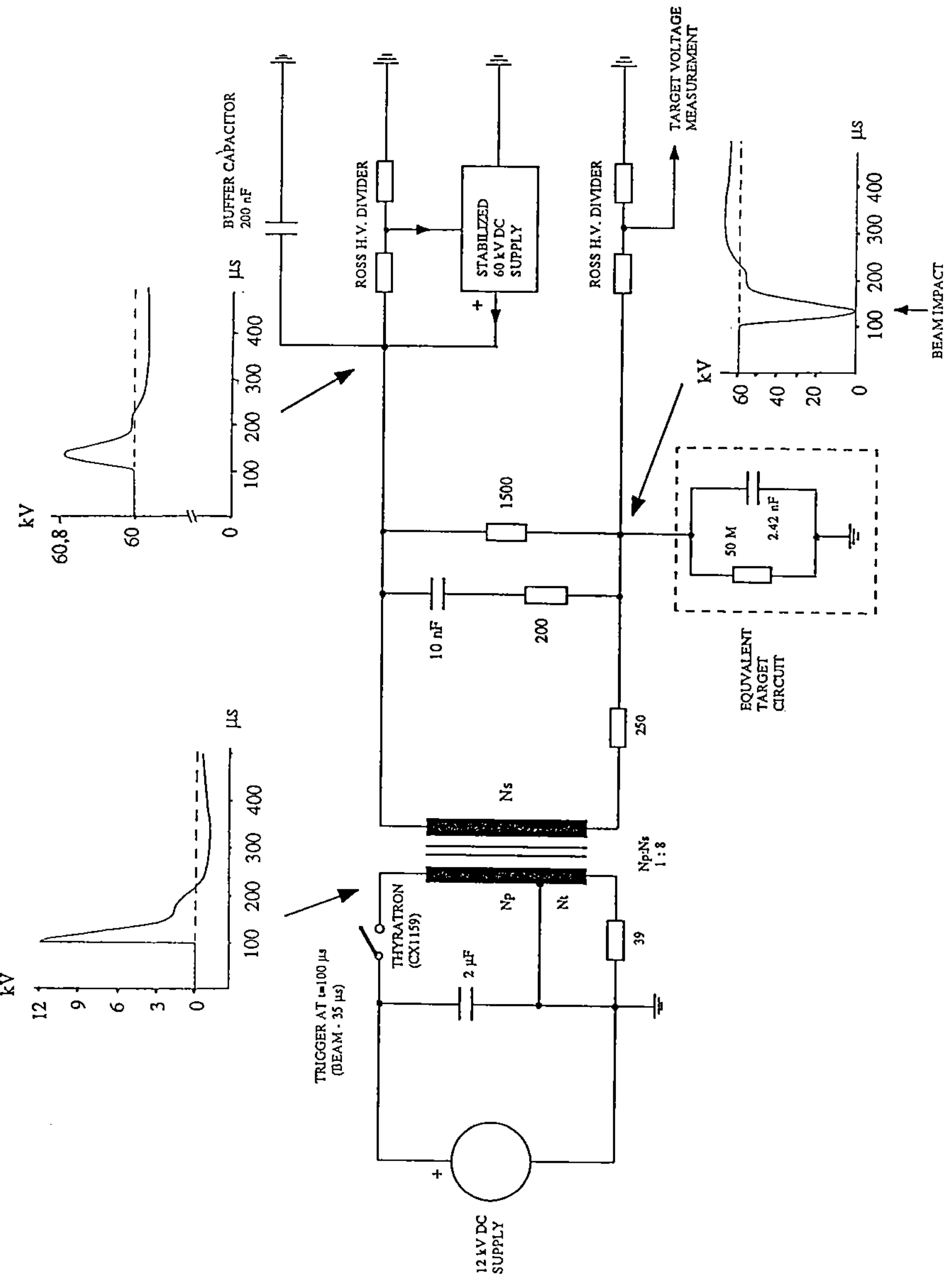

